\title{
LA CRÍTICA PIONERA DEL DICGIONARIO ACADÉMICO: EL MANUSCRITO SOBRE LAS VOCES MURCIANAS (1888) DE E. SAAVEDRA
}

El objeto de este trabajo se centra fundamentalmente en la edición y el estudio de un manuscrito cuyo contenido parece no ser conocido hasta la fecha dado que en la bibliografía especializada no figura referencia alguna al texto ${ }^{1}$. Su publicación, por tanto, puede contribuir, creemos, a perfilar un poco más la historia de la lexicografía española y, en concreto, la incipiente crítica al diccionario académico que comienza a desarrollarse en el siglo XIx. El texto, catalogado con la signatura 3-C-23 en la biblioteca de la Real Academia Española, está firmado en 1888 por Eulogio Saavedra y lleva por título "Lista de las voces que se emplean en el lenguage comun de este reino de Murcia". No se trata, como pudiera parecer por su encabezamiento, de un simple vocabulario regional. La "Lista" fue concebida por su autor como un estudio crítico y como una propuesta de enmienda de la duodécima edición, de 1884, del Diccionario de la RAE (DRAE). En cualquier caso, tanto si se considera de un modo - repertorio autónomo de murcianismos- como de otro - estudio sobre los regionalismos del DRAE- el texto de E. Saavedra presenta el notable interés de ser el primero realizado en su género. Pero antes de abordar la descripción del manuscrito propiamente dicha y su repercusión en el $D R A E$, el

${ }^{1}$ El manuscrito de E. Saavedra no aparece mencionado ni siquiera en los tratados más específicos que se refieren a algunos precedentes fechados, incluso, en años anteriores al del manuscrito 3-C-23. Por ejemplo, el apartado dedicado a los trabajos lexicográficos sobre el dialecto murciano incluido por J. García Soriano en los preliminares de su Vocabulario del dialecto murciano (C. Bermejo, Madrid, 1932; reimp. por la Editora Regional de Murcia en 1980). Tampoco se cita el manuscrito en la reciente monografía de J. MuNoz Garrigós y J. Perona, "Los vocabularios murcianos", en Vocabularios dialectales. Revisión crítica y perspectivas, ed. I. Ahumada, Universidad, Jaén, 1996. 
trabajo de Saavedra representa una buena oportunidad para exponer algunas consideraciones preliminares a propósito de su vinculación con una tradición de la lexicografía hispánica fecunda en trabajos de naturaleza similar.

EL FRÁGIL CUESTIONAMIENTO DE LA PLURALIDAD GEOLINGÜÍSTICA TRANSMITIDA POR EL “DRAE"

Hemos afirmado en otro lugar que los estudios sobre los regionalismos de los diccionarios $-\mathrm{y}$, en concreto, sobre los incluidos en el diccionario académico- constituye una de las propiedades distintivas de la metalexicografía española ${ }^{2}$, la cual se halla condicionada, a su vez, por los rasgos que han singularizado históricamente a la lexicografía hispánica frente a las de su entorno cultural. Estos son, entre otros, el dominio que, casi en régimen de monopolio, ha ejercido el DRAE entre los diccionarios de lengua y la atención prestada en él, desde sus inicios, al léxico considerado dialectal o regional. Esta situación ha venido acompañada, en el plano lexicográfico, por la publicación de multitud de vocabularios regionales en España y en América, confeccionados con el objetivo de complementar al DRAE y orientados por el deseo tenaz de enmendar la información geolingüística que proporciona el repertorio académico ${ }^{3}$.

${ }^{2}$ Cf. J. L. Aliaga, "Veinticinco años de teoría lexicográfica. Sobre el Étude linguistique et sémiotique de J. Rey-Debove", Studium. Revista de Humanidades. Homenaje al profesor Antonio Gargallo Moya, Facultad de Humanidades y Ciencias Sociales, Teruel, 1997, p. 25. En este mismo trabajo nos hicimos eco de las diferentes posturas existentes sobre el término metalexicografía y sobre el objeto de estudio de ésta entendida como teoría de la lexicografía. Aunque participamos de las ideas que L. F. LARA ha expuesto en varias ocasiones a propósito de esta cuestión (véase, por ejemplo, su Teoría del diccionario monolingüe, El Colegio de México, México, 1997, pp. 17-19) hacemos uso del término metalexicografía para referirnos, entre otras cuestiones, a la historia y a la crítica de los diccionarios debido a la aceptación que ha alcanzado ya la citada denominación, sobre todo en las investigaciones europeas.

${ }^{3}$ Entre los varios trabajos que presentan un estado de la cuestión sobre los repertorios de regionalismos del español pueden consultarse los de G. HaEnsch, "Dos siglos de lexicografía del español de América: lo que se ha hecho y lo que queda por hacer", en Unidad y variación léxica del español de América, eds. G. Wotjak y K. Zimmermann, Vervuert, Frankfurt, 1994, pp. 3981 y M. Alvar EzQUerra, "Los regionalismos en los diccionarios y vocabularios regionales", Lenguas peninsulares y proyección hispánica, ed. M. Alvar López, Fundación Fiedrich Ebert-ICI, Madrid, 1986, pp. 175-197. Para una 
La reiteración con que se ha acometido la tarea de elaborar vocabularios de regionalismos y la profusión de estudios críticos sobre el DRAE centrados en este mismo punto pone de manifiesto que la presentación que la lexicografía académica ha ofrecido de la diversidad espacial del español se ha considerado insistente y abiertamente insatisfactoria. Sin embargo, estos esfuerzos, prácticos y teóricos, volcados hacia el DRAE - y casi sólo hacia el $D R A E$ - representan al mismo tiempo, de forma paradójica, una muestra de aceptación del statu quo de la lexicografía hispánica. Y ello porque la mayor parte de los trabajos aludidos se ha apoyado, implícita o explícitamente, en una premisa que dista mucho de ser admisible. A saber, que el vocabulario no marcado en el $D R A E$ es, efectivamente, el léxico general del español y que, en relación con este español general, el aspecto más objetable de la práctica lexicográfica académica reside en la tardanza con que se nutre de neologismos. Incluso muchos de los trabajos más recientes que han intentado poner de relieve la debilidad de las informaciones dialectales del DRAE confrontándolas con los resultados sistemáticos de la lingüística no han cuestionado el alcance de la representatividad geográfica y normativa del léxico no marcado en el repertorio de la Real Academia Española.

Por otro lado, no faltan autores que se muestran sorprendidos por la casi nula incidencia de todos estos estudios y vocabularios sobre la práctica lexicográfica académica. A este respecto parece haberse olvidado, en ocasiones, que el DRAE es un repertorio con pasado, rehecho sólo en aspectos parciales sobre un modelo que, en lo esencial, sigue siendo el del Diccionario de Autoridades (1726-1739) - o, si se prefiere, el de la primera edición sin autoridades, de 1780- y que, en consecuencia, no tolera bien una reestructuración en función de las exigencias científicas actuales. Y tampoco se ha considerado suficientemente, creemos, lo que podríamos denominar lógica interna de la institución académica: su modo de hacer lexicografía no ha previsto, hasta la fecha, el aporte de colaboraciones externas - con independencia de su rigor- como parte del mecanismo regular para la revisión del diccionario.

revisión crítica de los estudios metalexicográficos sobre los regionalismos del español puede verse J. L. AliAga, "Diatopic labelling in Spanish lexicography: A critical revision and new perspectives", CLex, 1999, núm. 69 (en prensa). 
Sin necesidad de recurrir a ejemplos recientes resulta ilustrativo el caso de J. Borao quien publica su Diccionario de voces aragonesas en 1859 con el objetivo primordial de ser útil a la RAE, al igual que había ocurrido en 1836 con el Ensayo de un diccionario aragonés-castellano de M. Peralta, al que Borao intenta superar ${ }^{4}$. Sin embargo no fue hasta la decimoquinta edición del DRAE (1925) cuando la corporación decidió aprovechar, aunque con extremada cautela, el repertorio de Borao. Al erudito aragonés no le pasó inadvertido el nulo interés que su obra despertó entre los académicos de su época y en la segunda edición de su diccionario (1884) introdujo una nota en la que mostraba su decepción ante la indiferencia de la Academia por las voces aragonesas: "poco ha mejorado ésta [la Academia] esa parte de su obra, en los ciento cincuenta años que ha tenido para estudiarla, y no obstante el auxilio que nosotros le hemos ofrecido con la primera edición de nuestro Diccionario, publicada en 1859, la cual pudo aprovechar para la última del suyo, que es de $1869 " 5$.

Estas líneas no pretenden ser sino una muy concisa llamada de atención sobre un problema harto complejo del que no nos podemos ocupar en este trabajo. Sólo hemos querido poner de relieve que, si bien ha sido una constante la conciencia crítica respecto del modo en que nuestra lexicografía ha tratado los regionalismos, sólo una pequeña parte de las investigaciones ha cuestionado realmente el tratamiento lexicográfico de la diversidad geolingüistica del español, punto de vista este último que exige un planteamiento crítico, que ha faltado en general, sobre el registro del español general en los diccionarios. Por ello, la publicación del manuscrito de E. Saavedra, como primer testimonio conocido de la línea predominante de trabajos metalexicográficos que hemos comentado, es una buena oca-

${ }^{4} \mathrm{El}$ acta de la sesión académica del 22 de septiembre de 1859 da fe de que Borao envió personalmente a la RAE su Diccionario. En ella puede leerse la siguiente comunicación: "Del Diccionario de voces aragonesas que ha compuesto el sr. D. Jerónimo Borao recibió con aprecio la Academia un ejemplar remitido por el autor" (Archivo de la RAE, Actas, libro 23, 22-91859). Conviene precisar que, si bien cabe considerar a Peralta y a Borao como precedentes de Eulogio Saavedra en la evaluación de los regionalismos peninsulares del DRAE, Saavedra es el primero en confeccionar un trabajo específicamente pensado para la revisión del diccionario académico. Ello explica en parte que, a diferencia de los dos autores aragoneses, Saavedra no publicara su texto.

${ }^{5}$ Cf. J. Borao, Diccionario de voces aragonesas, Zaragoza, 1884, p. 143, nota. 
sión para sumarse a la redefinición de la lexicografía hispánica en los términos en que L. F. Lara la ha formulado recientemente ${ }^{6}$.

Por lo que respecta al tratamiento que la Real Academia Española vaya a otorgar a la diversidad geográfica del español en la vigésima segunda edición del DRAE - prevista para el año 2000- no parece que deba esperarse ningún tipo de ruptura con el pasado. Por un lado, la Asociación de Academias de la Lengua Española prepara desde hace tiempo un Gran Diccionario de Americanismos, complementario del DRAE, que bebe en la tradición de la lexicografía diferencial y subordinada que ha caracterizado históricamente al español de América ${ }^{7}$. Por otro lado, la nueva planta del DRAE con la que trabaja la Academia desde 1997 —esto es, los nuevos criterios de elaboración del diccionario-no introduce novedades significativas en este punto: mantiene esencialmente inalterados el número y el tipo de marcas geográficas, el orden de éstas en la microestructura (primero las de España) y los criterios de aceptación de voces dialectales. En definitiva, conserva esencialmente inalterada la concepción eurocentrista del español.

\section{EL ESTUDIO SOBRE LOS REGIONALISMOS MURCIANOS DEL "DRAE"} DE E. SAAVEDRA

No nos consta que E. Saavedra publicara obra alguna ni hemos podido obtener ningún dato de su biografía salvo el referido a su localidad de residencia, Lorca (provincia de Murcia) que figura en la carta de presentación del manuscrito incluida en nuestra edición. Parece tratarse, pues, de uno de tantos ciudadanos anónimos que con frecuencia dirigen a la Academia, sintiéndose partícipes de su labor, no pocas observaciones y sugerencias $^{8}$. Pero la tarea de Saavedra plasmada en el manuscrito que aquí editamos no se reduce a una advertencia aislada sobre

6 Cf. "Por una redefinición de la lexicografía hispánica", NRFH, 44 (1996), 345-364.

7 Cf. H. López Morales, "Rasgos generales”, en Manual de dialectología hispánica. El español de América, dir. M. Alvar, Ariel, Barcelona, 1996, pp. 19-27.

8 Puede consultarse, a este respecto, el trabajo de G. Salvador, "El diccionario y la gente", en Jornadas de filología. Francisco Marsá, Universitat, Barcelona, 1990, pp. 193-207. Desde el mes de octubre de 1998 la Academia cuenta con una página web desde la que los particulares pueden comunicar sugerencias o formular consultas ortográficas y gramaticales. 
tal o cual voz como puedan ser la mayor parte de las observaciones aludidas. Antes bien, está configurada como un trabajo de las mismas características y, salvando las distancias, del mismo rigor que los estudios sobre los dialectalismos del diccionario académico surgidos desde el nacimiento de la metalexicografía tal como se entiende hoy 9 .

El texto carece, lógicamente, de preliminares dedicados a consideraciones teóricas o metodológicas que, por lo demás, se echan de menos en no pocos de los estudios más recientes de tema similar. Por otro lado, la fuente de datos para Saavedra no es otra que la observación personal del habla oral. Así pues, sólo la carta de presentación que encabeza el manuscrito aporta algunos indicios sobre las ideas lingüísticas del autor. Su contenido deja entrever que Saavedra se muestra consciente, por ejemplo, del notable valor lingüístico-etimológico y etnográfico de los regionalismos, valor que sólo recientemente, tras la publicación de los primeros atlas lingüísticos de la Península ibérica, ha sido sistematizado y relacionado con la práctica lexicográfi$\mathrm{ca}^{10}$. Asimismo, Saavedra funda el interés de su vocabulario en el provecho que de él puedan obtener los hablantes no nativos de la región, desconocedores por lo general de las peculiaridades léxicas dialectales que forman parte de la norma de uso de la zona. Por lo demás, la motivación de la obra de Saavedra hay que buscarla -según expone en la mencionada carta- en la solicitud de colaboración que la Academia insertó en la "Advertencia” del diccionario de 1884 (“...siempre recibió y recibirá la Academia con íntimo júbilo el amparo de los entendidos y del público en general").

Y lo cierto es que, aparte del texto de Saavedra, la duodécima edición del DRAE (1884) fue objeto de numerosas observaciones publicadas ${ }^{11}$, hasta el punto de llegar a ser la más

${ }^{9}$ Sobre las obras precursoras de la teoría lexicográfica actual véase el trabajo de F. J. Hausmann, "Pour une histoire de la métalexicographie", Wörterbücher. Dictionaries. Dictionnaires. Ein internationales Handbuch zur Lexicographie, eds. F. J. Husmann et al., W. de Gruyter, Berlin-New York, 1989, t. 1, pp. 216-224.

10 Cf. J. Fernández-Sevilla, Problemas de lexicografía actual, Instituto Caro y Cuervo, Bogotá, 1974, pp. 81-113 y M. Alvar, “Atlas lingüísticos y diccionarios", LEA, 4 (1982), 253-323.

${ }^{11}$ Cf., por ejemplo, las siguientes: F. Rodríguez Marín, De Academiae caecitate, reparos al nuevo Diccionario de la Academia, Madrid, 1887; F. CoMmelerán, El Diccionario de la Lengua Castellana por la Real Academia Española, Pérez Dubrull, Madrid, 1887; A. DE Valbuena, La fe de erratas del nuevo Diccionario de 
comentada $-\mathrm{y}$ reprobada- de todo el siglo xix. Pero todo hace pensar que la demanda de cooperación de la Academia difundida en los preliminares del diccionario de 1884 no iba más allá de una formulación retórica ya que la corporación archivó durante décadas el texto de Saavedra (al menos, no hizo uso de él hasta bien entrado el siglo xx, como veremos). Tampoco parece que los intereses académicos de la época fueran los más favorables para que el manuscrito de Saavedra gozara de una acogida más entusiasta. Se da la circunstancia de que la duodécima edición del DRAE y la siguiente, de 1899, destacan por alcanzar el punto más bajo, cuantitativa y cualitativamente hablando, en la apreciable despreocupación por el léxico regional que trasluce el diccionario durante todo el siglo xIx (sobre todo desde la sexta edición, de 1822) ${ }^{12}$.

En el aspecto puramente material, el manuscrito se compone de cuarenta y un folios. De ellos, treinta y ocho, numerados con cifras arábigas, contienen el cuerpo del vocabulario y están precedidos por la carta de presentación y por la portada en la que figura el título - numeradas ambas con cifras romanas-y una cubierta, sin numerar, que repite el título de la portada y que probablemente fue añadida por la Academia para asegurar la conservación del texto. Resulta digno de destacar el hecho de que Saavedra divida el manuscrito en cuatro apartados que se corresponden con las distintas situaciones que el autor considera a propósito de la relación entre las voces murcianas y el diccionario académico. Con ello Saavedra está prefigurando la estructura de los estudios lexicográficos contemporáneos sobre los regionalismos de los diccionarios. En el texto se examina un total de cuatrocientas cincuenta y siete vo-

la Academia, Madrid, 1887, 2 ts.; B. Rivodó, Voces nuevas en la lengua castellana. Glosario de voces, frases y acepciones usuales y que no constan en el Diccionario de la Academia (12a ed.), Paris, 1889; M. Atrián y SAlas, La crítica del Diccionario de la Academia, Teruel, 1887.

12 Esta observación está sustentada en el estudio de la evolución del corpus de voces aragonesas en el DRAE que, como es sabido, constituye el más numeroso de entre las voces con marca geográfica en el diccionario de la Academia. Quizá convenga aclarar que el examen de la trayectoria completa del DRAE impide interpretar lo que hemos considerado despreocupación como el resultado de algún planteamiento novedoso sobre el léxico del español. Cf. J. L. Aliaga, Aspectos de lexicografía española. El léxico aragonés en las ediciones del diccionario académico, Institución "Fernando el Católico", Zaragoza, 1999 (en prensa). 
ces. De ellas cuatrocientas veinte pertenecen a la primera parte, que ocupa la porción más extensa del texto (ff. 1 a 34) y contiene un conjunto léxico dialectal murciano (voces y acepciones) cuya entrada en el DRAE propone Saavedra. Asimismo, forman parte de este apartado las voces que, aun contando con una entrada o acepción en el diccionario académico, carecen de la marca regional murciana que aconseja Saavedra. El segundo apartado (ff. 35 y 36) consta de catorce artículos que encierran algunas enmiendas a la microestructura de voces marcadas como murcianas en el DRAE de 1884. En la tercera sección (f. 37) se mencionan trece entradas de esta misma edición del DRAE que poseen una indicación de uso regional a la que debe sumarse, a juicio de Saavedra, la murciana. Finalmente, en un cuarto apartado (f. 38) se citan diez vocablos del DRAE con una marca murciana cuya supresión propugna el autor del manuscrito.

Las voces de cada uno de los cuatro apartados están ordenadas alfabéticamente (con la $c h$ y la $l l$ como letras independientes). En cuanto transcripción gráfica del texto hemos preferido mantener todas las peculiaridades que presenta el manuscrito. Así pues, pueden apreciarse en él algunos usos gráficos que desde el punto de vista normativo podrían estimarse como errores, considerando incluso la ortografía oficial vigente en la época. Sin embargo, apenas hemos apreciado irregularidades en la ordenación de las entradas en el interior de cada letra. Además, el texto está redactado con sumo cuidado, sin enmiendas ni tachaduras y haciendo uso, con el objeto de discriminar informaciones, de diversos recursos gráficos, a imitación de los convencionalismos de los textos lexicográficos impresos. Todo ello hace pensar en el manuscrito como fruto de una elaboración meditada y consciente, es decir como redacción definitiva de unos materiales acopiados originalmente de modo distinto (en pliegos, en fichas, etc.). A pesar de ello, en el primer apartado (ff. 1 a 34) Saavedra reserva un espacio en blanco al final de cada letra para poder introducir los datos que hubiera podido reunir una vez iniciada la redacción del texto. No parece que fuera así ya que en ese lugar no figura ninguna entrada que rompa la ordenación alfabética.

Únicamente en la primera parte (ff. 1 a 34) y en la segunda (ff. 35 y 36) pueden hallarse entradas redactadas en forma de artículos de diccionario mediante el uso de las técnicas y las convenciones lexicográficas usuales. En las otras dos partes del manuscrito se proponen enmiendas que no requieren la redac- 
ción de artículos completos. Desde el punto de vista semántico, los núcleos temáticos que aglutinan la mayor parte del vocabulario pertenecen al ámbito de la vida cotidiana del mundo rural: la naturaleza (animales, vegetación, árboles, frutos, tareas del campo...), el ser humano (cuerpo, movimientos, acciones, enfermedades...), la vivienda (partes y objetos de la casa), etc. En cuanto a la presentación de los artículos, es preciso insistir en la voluntad de Saavedra de distinguir las distintas informaciones recurriendo a variadas grafías y trazos de letra -rasgos que se respetan en esta edición- con el objeto de facilitar al máximo el aprovechamiento de los materiales por parte de la Academia. Así, el vocablo de la entrada está caligrafiado con trazo grueso y con un tipo de letra mayor que el utilizado para el resto del artículo. Con letra de menor tamaño, aunque asimismo con trazo grueso, Saavedra transcribe las unidades fraseológicas que constituyen una subentrada, las escasas etimologías que aventura y las definiciones sinonímicas. La categoría gramatical, las definiciones perifrásticas, las sinonímicas múltiples, además de otros comentarios esporádicos, aparecen con un trazo de letra fina y cursiva. Finalmente, las marcas de registro están redactadas con letra fina y redonda ${ }^{13}$.

Lo señalado hasta ahora proporciona ya una idea aproximada de la riqueza de informaciones que componen los artículos del manuscrito y del notable manejo - poco común en la época- de la redacción lexicográfica por parte de Saavedra. Desde este último punto de vista, su vocabulario se muestra como un texto lexicográfico sensiblemente más evolucionado, más moderno si se prefiere, que los de sus predecesores M. Peralta y

${ }^{13}$ Las definiciones sinonímicas simples transcritas con trazo grueso son, en realidad, reproducciones de entradas del DRAE cuyo contenido definitorio en éste coincide con el del vocablo-entrada del manuscrito cuya introducción en el diccionario académico propone Saavedra. Sólo las definiciones sinonímicas simples que no remiten al DRAE, como las de bartola, jalar, llampear, llampo y nora presentan el mismo tipo de letra que las definiciones perifrásticas. En el caso de las entradas apencary atochada la letra fina cursiva con que transcribe las equivalencias en el DRAE (arrostrar y caballón, respectivamente) debe atribuirse a un descuido involuntario ya que, a continuación, Saavedra indica el número de acepción del DRAE al que se refiere en cada caso. La referencia a las acepciones del DRAE se precisa también en ciertas definiciones perifrásticas cuando incluyen alguna palabra polisémica que conviene puntualizar, como en los artículos mantorna y picola entre otros: "mantorna $\mathrm{f}$. La segunda reja ( $3^{\mathrm{a}}$ acepción) que se da en una barbechera"; "picola f. Especie de pico ( $3^{\mathrm{a}}$ acepción) pequeño que tiene un uso especial". 
J. Borao (véase nota 4). Aunque preferimos considerar el manuscrito de Saavedra como un estudio crítico sobre el DRAE antes que, simplemente, como un glosario de murcianismos, la organización del texto permite examinarlo con más detalle, con las salvedades necesarias, en función de los componentes y estructuras habituales de los diccionarios.

A la macroestructura nos hemos referido parcialmente más arriba (número de entradas, partes del texto, ordenación alfabética del material y núcleos temáticos a los que se refiere el léxico acopiado). Cabe añadir ahora algunas precisiones. La mayoría de los vocablos-entrada pertenece a las categorías sustantiva y verbal. Escasean los adjetivos y aparecen algunas unidades fraseológicas y lexías complejas lematizadas, aunque la mayor parte de éstas figura en la microestructura. Los vocablosentrada se presentan, por lo general, con la neutralización de las marcas gramaticales con que suelen lematizarse en los diccionarios. No obstante, algunos sustantivos con moción numérica figuran en su forma plural debido, con toda probabilidad, a su escaso uso en singular -aunque no se advierta de ello- por remitir a realidades consideradas generalmente de forma múltiple (alatones, alcazabas, arreboleras, asperillas, bolas y bolicas, cernederas, gallegas, golfos, hierros, llandas, minchirones, moragas, pasos, pelados, torradas, vergas). Por otra parte, dejando de lado las entradas dobles debidas a la moción de género (campero, $a$; chepado, a; chino, a; doblero, a; garranchoso, a; jabato, a; panocho, a; platero, a; rabotero, a; salsero, a; señor, a) recoge Saavedra bajo una misma entrada formas léxicas que, con el mismo contenido, presentan alguna discrepancia fónica o morfológica (chaparra o chaparro, chisclo o chiscle, chorreada y chorreon, enronar y enrunar, escandalina y escandalizo, harpily jarpil, morra y morron, piola y piula).

En lo que se refiere a la microestructura, hay que apuntar que los artículos de las dos primeras partes del manuscrito pueden clasificarse en dos grandes grupos: el de los artículos que incluyen una definición directa y el de los que remiten a una definición del DRAE mediante la mención de una entrada de éste en la microestructura, con distinta grafía, según se ha comentado más arriba, y con indicación de la acepción concreta del $D R A E$ en su caso. Véanse cuatro ejemplos, dos del primer tipo y dos del segundo:

aporrecear v. a. Llamar á una puerta con golpes violentos y repetidos. 
magencar ver. a. Cavar la tierra someramente sin profundizar mucho.

cascarrar ver. a. Cascar, $1^{\mathrm{a}}$ acepción. U.t.c.r. naya $\mathrm{f}$. Meseta ó rellano de escalera.

Como se aprecia en los ejemplos anteriores, Saavedra hace uso, casi sistemáticamente, de abreviaturas que señalan la categoría gramatical y de las relativas a los cambios de categoría verbal, de transitivo a reflexivo ("U.t.c.r.") y nominal, de adjetivo a sustantivo ("U.t.c.s."). No faltan otras, más esporádicas como Fig. para indicar las transiciones semánticas en los artículos polisémicos, como en los siguientes ejemplos:

despatarragarse ver. rec. (Familiar) Colocarse estando de pié con las piernas muy abiertas. Fig. Ponerse en lo firme. Salir por lo alto en un trato á ajuste.

repropiarse ver. Contenerse, afirmarse el que tropieza ó resbala y va á caer. Fig. Contenerse en un arrebato de ira ú obcecación.

El deseo de precisión a la hora de informar sobre la estimación social de los murcianismos es una de las cualidades más apreciables del manuscrito. Las marcas de uso figuran casi siempre sin abreviar, entre paréntesis y en un lugar fijo del artículo (entre la categoría gramatical y la definición). Así, por ejemplo, Saavedra circunscribe a los niveles subestándar de lengua el ámbito de empleo de numerosas voces. Pueden hallarse setenta y una voces o acepciones con la indicación de uso familiar y doce con la de vulgar. Esporádicamente, el autor da cuenta de otras limitaciones en el empleo de ciertas voces sobre las que emite un juicio de frecuencia de uso (barzoque, oripié, percanzar); que estima propias del lenguaje de la agricultura (saque) o de la minería (anchuron) o que adscribe a una situación comunicativa en que predomina un tono despectivo (arrufaldarse, palabrota$d a$ ). La siguiente muestra presenta algunas de las informaciones de uso mencionadas que, en ocasiones, se combinan en un mismo artículo:

barzoque m. (Familiar) Diantre; demontre. Anda que te lleve Barzoque, es frase muy usada por aquí.

desforrinchar ver. n. (Familiar) Reventar, estallar con ímpetu en sentido material ó figurado. Usase tambien como recíproco. timple m. (Vulgar) Tiple, guitarra pequeña de voces agudas. 
saque m. (Familiar) Salida. Buscar el saque a un negocio; no tiene saque. En agricultura, el sitio de la salida del agua en una acequia ó brazal comun.

De todo lo dicho se deduce ya que, a pesar de no tratarse de un texto pensado para su publicación, la microestructura de los artículos presenta un notable grado de normalización. Sin embargo, a nuestro juicio, el aspecto que mejor revela las excelentes cualidades de Saavedra para la lexicografía reside en la confección de las definiciones. Dejando aparte los artículos que conscientemente remiten al $D R A E$, el lexicógrafo murciano muestra una marcada preferencia por las definiciones de tipo perifrástico, circunstancia que adquiere aquí cierta relevancia. Téngase en cuenta que la lexicografía dedicada al inventario de regionalismos (incluida la lexicografía general) ha relegado a un plano de importancia menor la presentación del significado de aquéllos y ha recurrido con excesiva frecuencia al expediente de remitir al sinónimo de la variedad de referencia (la lengua general o, mejor, la lengua no marcada en el $D R A E$ ). Por ello, la inclinación de Saavedra por las definiciones perifrásticas avala nuestra valoración anterior sobre la modernidad lexicográfica del manuscrito y se relaciona con las ideas expresadas en la carta de presentación en las que Saavedra explica el enfoque práctico con que concibe su labor ("la esplicación [de los regionalismos] es indispensable para los que viajan por la región en que se emplean...”).

\section{LA REPERCUSIÓN EN EL “DRAE” DEL ESTUdio DE E. SAAVEDRA}

El origen de las voces marcadas como murcianismos en el diccionario académico es relativamente bien conocido. Las voces murcianas destinadas a su inclusión en el Diccionario de Autoridades fueron remitidas desde Murcia a la Real Academia Española por Victoriano Alcázar, sobrino de Bartolomé Alcázar, miembro fundador de la Academia14. Según el recuento de A.

${ }^{14}$ Cf. Archivo de la Real Academia Española, Actas, libro I, 13-5-1714, 20-51714 y 3-12-1716. Las dos primeras fechas corresponden a las sesiones académicas en las que se dio cuenta de los envíos de las voces pertenecientes a las letras $a$ y $b$, respectivamente. La tercera fecha se refiere al envío del resto de voces. Después de esa última fecha, las actas de las sesiones académi- 
Salvador, ascienden a ciento sesenta y siete las localizaciones regionales murcianas presentes en el primer diccionario académico ${ }^{15}$. Por su parte, J. García Soriano reseña brevemente la suerte de los murcianismos en el DRAE hasta la $14^{\text {a }}$ edición (1914), momento en el que habían quedado reducidos a unos ciento veinticinco. El incremento de voces regionales que inundó la $15^{\mathrm{a}}$ edición del repertorio académico (1925) alcanzó también a las voces y acepciones murcianas que aumentaron hasta la cifra de doscientas ochenta, aproximadamente. Este corpus ha experimentado alguna variación en las entregas posteriores del $D R A E$ ya que son trescientas ochenta y dos las localizaciones murcianas en la $21^{\text {a }}$ edición (1992) ${ }^{16}$.

De lo anterior se deduce que, al igual que ocurrió con la tarea de Peralta y Borao, la Academia se desentendió del trabajo de Saavedra durante varias décadas, ya que las voces murcianas apenas experimentaron modificaciones de las ediciones $13^{\underline{a}}$ (1899) y 14 a (1914) del DRAE. No obstante, la aludida indiferencia no estaba relacionada con un juicio negativo de la Academia sobre las propuestas del autor murciano o, al menos, no condicionó la actuación de la siguiente generación de académicos, como se verá. Así, de las ciento cincuenta y ocho nuevas voces y acepciones murcianas de la 15 $5^{\text {a }}$ (1925), sólo dieciocho se pueden leer en las páginas del manuscrito de Saavedra ( $a b u$ zarse, arrufaldarse, capacear, capaza, capuzón, carral, cascaruja, cejo, desperfollar, falsa, golfo, infantillo, jetazo, molla, nora 'guindilla', panocho, salsear y salsero). Sin embargo, las apreciables discrepancias entre la información que facilita Saavedra a propósito de tales voces y la que figura en el DRAE no permite afirmar con seguridad que el manuscrito sirviera de fuente para la mayoría de ellas. Por lo que respecta a las treinta y siete enmiendas propuestas por el autor murciano en los apartados segundo, ter-

cas ya no mencionarán, durante los siglos XVIII y XIX, colaboración alguna proveniente de la región murciana.

15 Cf. A. Salvador, "Las localizaciones geográficas en el Diccionario de Autoridades", LEA, 7 (1985), p. 127.

16 En el recuento se han desechado las referencias a la región murciana que no tenían carácter lingüístico. Cf. Real Academia Española, Diccionario de la lengua española, Espasa-Calpe, Madrid, 1995 (ed. en CD-ROM). También puede verse la compilación extraída de la misma fuente por parte de J. Muñoz Garrigós y J. Perona, Murcianismos. Términos murcianos incluidos en el Diccionario de la Real Academia, Publicación monográfica del Diario 16, Murcia, 1995, núm. 3. 
cero y cuarto de su estudio, sólo tres (fosca, mampirlan y vargano) parecen haberse materializado en el diccionario entre 1899 (13 $3^{\underline{a}}$ ed.) y 1925 (15 ${ }^{\underline{a}}$ ed.).

Pero es necesario abordar el examen de las ediciones posteriores a la de 1925 para poner de manifiesto unos hábitos lexicográficos que, no por resultar poco comprensibles, han sido menos frecuentes en el devenir del diccionario académico. Para ello conviene tener presente que la obra de conjunto más solvente, todavía hoy, sobre el léxico regional murciano, la de J. García Soriano, fue publicada en 1932, varios años antes, por lo tanto, de la aparición de la $16^{\mathrm{a}}$ edición del DRAE (1936-39). Además, el Vocabulario del dialecto murcianofue premiado en concurso público por la Real Academia Española. Sin embargo, la cuidada y copiosa información de los tres mil quinientos artículos que García Soriano puso a disposición de la Academia no fue obstáculo para que ésta rescatara, precisamente a partir de ese momento, el contenido del ya remoto manuscrito de E. Saavedra, el cual pasó a nutrir las columnas del DRAE de forma mucho menos equívoca que la que es posible certificar para la edición de 1925.

Aparte de voces como amorgonar o garigola, cuya localización murciana puede deberse tanto a Saavedra como a García Soriano, que presentan datos semejantes al respecto, encontramos un conjunto de informaciones que procede, sin asomo de duda, del manuscrito de 1888 . Se trata, en primer lugar, de aquellas palabras o informaciones sobre el uso regional murciano propuestas por Saavedra que no figuran en la obra de García Soriano y que aparecen en el DRAE a partir de su $16^{\mathrm{a}}$ edición (amasadera, cerchear, pichona, plantonar, platero y posete). Obsérvese la coincidencia de los siguientes artículos:

pichona $\mathrm{f}$. Un juego de naipes de azar, usado entre la gente vulgar. [Saavedra]

pichona. 2. Murc. Juego de naipes usado entre gente del pueblo. [DRAE 1936 o ss.]

platero, a adj. Que se aplica á los asnos cuyo color es gris plateado. U.t.c.s. [Saavedra]

platero. 3. adj. Murc. Se dice de los asnos cuyo color es gris plateado. Ú.t.c.s. [DRAE 1936 o ss.]

posete $\mathrm{m}$. Destilador ó pié de jarra. [Saavedra]

posete. 1. m. Murc. Destilador o pie de jarra. [DRAE 1936 o ss.] 
Pero resulta todavía más significativa si cabe, la presencia en el DRAE posterior a 1936 de informaciones que, encontrándose en el repertorio de García Soriano, son tomadas por la Academia del estudio de Saavedra (gachasmigas, nispolero, pereta, peretero, piñuelo, timple, zarangollo y zofra $)^{17}$. Compárense los testimonios que disponemos a continuación por orden cronológico (Saavedra, García Soriano y DRAE de 1936-39 o posterior):

gachasmigas $\mathrm{f}$. Especie de migas ( $6^{\mathrm{a}}$ acepción) hechas con harina en vez de pan desmenuzado. [Saavedra]

gachasmigas. f. pl. Migas que se hacen con harina de maíz, pimentón, cebolla, aceite y agua. [García Soriano]

gachasmigas f. pl. Murc. Especie de migas hechas con harina en vez de pan desmenuzado. [DRAE 1936 o ss. $]$

pereta $f$. Clase de pera pequeñita y temprana. [Saavedra]

pereta. f. Variedad de pera de tamaño muy pequeño, que en las ramas forman racimos. Se las llama también peretas de la reina, y en Castilla "peras de San Juan", por ser a fines de junio la época de su cosecha. [García Soriano]

pereta f. Murc. Clase de pera pequeñita y temprana. [DRAE 1936 o ss.]

zarangollo $\mathrm{m}$. Fritada de calabaza, cebolla y tomate a los que suelen añadirse otros adherentes. [Saavedra]

zarangollo. m. Pisto. [García Soriano]

zarangollo Murc. Fritada de calabaza, cebolla y tomate a los que suelen añadirse otros ingredientes. [DRAE 1936 o ss.]

\section{VALORACIÓN FINAL}

El manuscrito de 1888 de Eulogio Saavedra puede ser considerado, en una primera aproximación, como una venerable pieza desconocida de la lexicografía española, lo cual ya justificaría con creces la atención que le hemos dedicado aquí. Pero la "Lista de las voces que se emplean en el lenguage comun de este reino de Murcia" presenta, al menos, otros dos puntos de interés que le otorgan, a nuestro juicio, un valor singular. Representa, por un lado, el anticipo decimonónico del sueño perseguido sin éxito por los estudios metalexicográficos de fina-

17 El análisis de la evolución interna del diccionario académico proporciona numerosos ejemplos de prácticas lexicográficas similares a la descrita aquí. Cf. nuestro trabajo citado en nota 12. 
les del siglo xx: el deseo de intervenir de forma efectiva en la peculiar presentación del español que viene sancionando históricamente la Academia. Por otro lado, la "Lista" se nos revela como una nueva piedra de toque con la que seguir desconstruyendo la práctica lexicográfica académica, favorecida, quizá como ninguna otra de su entorno, por los mitos que muchos usuarios atribuyen al diccionario.

José Luis Aliaga

Universidad de Zaragoza

\author{
APÉNDICE \\ LISTA DE LAS VOCES QUE SE EMPLEAN EN EL LENGUAJE COMÚN DE \\ este REINo de Murcia, por D. Eulogio SAAvedra
}

\title{
[f. Ir] A la Real Academia Española
}

Alentado por la generosa invitación/ que al terminar la Advertencia que encabeza/ la última y excelente edición del Diccionario/dirige al público en general esa ilustre Corpo-/ración, me atrevo á ofrecerle respetuosamente/ la adjunta lista de voces que se emplean en el lengua-/ ge común de este reino de Murcia./

Aun que es humilde la materia,/ no deja de ofrecer interés, pues los provincia-/lismos además de formar parte integrante/ del caudal de nuestro idioma, suelen con-/servar curiosas muestras del origen etimológi-/co de las voces, ó rastros de su estructura an-/tigua y de usos y costumbres que ya pa-/saron; sobre todo su esplicación es indispen-/sable para los que viajan por la región/ en que se emplean, ó tienen negocios en ella,/ para los funcionarios públicos que pasan/ á la misma, sino han de incurrir en errores/ lamentables como con frecuencia sucede, y/ para todos los que dicen conocer á fondo/ y en detalle la lengua patria./

Por eso la Academia da cabida/ en su Diccionario á las voces provinciales de/ los reinos en que se dividió nuestra monarquía./ Quizá no todas las contenidas en la adjunta/[f. Iv] lista tengan este carácter puramente local/ pero nosotros nos hemos ceñido sencilla-/mente á anotar lo que oíamos hablar en/ este país, dejando á la jurisdicción aca-/démica, única competente, la convenien-/te calificación de las voces./

Juzgaré ampliamente recompen-/sado mi modesto é imperfecto trabajo si la Real Academia se digna admitirlo,/ por si de algo puede servirle en sus estu-/dios habituales para las sucesivas edicio-/nes del Diccionario nacional, obra grandiosa pero lenta y difícil, si ha de al-/canzar la perfección por todos deseada./

Lorca 30 de Noviembre de 1888/

[firma] Eulogio Saavedra/ 
[f. IIr] Lista de las voces que se emplean en el lenguage comun de este reino de Murcia

[f. 1] Voces usadas en el lenguage comun de este reino de Murcia, que no se encuentran en la última edicion del Diccionario de la Real Academia Española

abusión f. (Vulgar) Superstición, falsa creencia ó preocupación en la acepción $3^{\underline{a}}$ del Diccionario.

abuzar Echarse de bruces, especialmente para beber agua en los rios ó charcos. U.t.c.r.

aceña $\mathrm{f}$. Noria de riego.

acibatar ver. a. (Familiar) Tambien se dice aciguatar. Apercollar, acogotar, entrecoger á alguno y castigarlo duramente.

airazo m. Ventarrón.

alatonero m. Almez.

alatones m. Almezas, fruto del almez.

alazor m. Azor.

alcazabas f. Cañas secas del maiz.

aldaba morisca $\mathrm{f}$. Aldaba, en la $2^{\mathrm{a}}$ acepción del Diccionario, que sugeta y asegura la puerta ó ventana donde se coloca por medio de un gancho movible.

alcancil $m$. Alcancil, alcachofa.

almaina f. Almadana, almadena, almadina./[f. 2]

amasadera f. Cuezo ó artesilla en que amasan el yeso los albañiles.

amorgonar ver. a. Amugronar.

amposta $\mathrm{f}$. Sitio en descampado donde poder resguardarse del viento u ocultarse con un objeto determinado.

ampostarse ver. r. Resguardarse en descampado de la lluvia ó viento al abrigo de un arbol, peña, tapia ú otro accidente del terreno. Ocultarse en la misma forma para esperar en acecho ú otro fin.

anchuron $\mathrm{m}$. Sitio despejado de edificios, de arboles, de malezas \&. En mineria socabon ó espacio ancho en las galerias subterraneas.

anchoa $\mathrm{f}$. Pez marino salado ó sin salar.

angeo $\mathrm{m}$. Clase de lienzo usado antiguamente. Usola Gongora en aquellos versos: Descosed y desnudad/las tocas de angeo rudo.

anieblarse ver. r. Secarse la fruta antes de madurar por efecto de las nieblas ú otras causas admosfericas.

apabilarse ver. r. (Familiar) Aterrorizarse, pasmarse, quedarse sin acción por efecto del miedo.

apartador m. Utensilio de cocina donde se colocan las vasijas que se sacan del fuego muy calientes.

apencar v. a. (Familiar) Arrostrar, $2^{\underline{a}}$ acepción.

aporrecear v. a. Llamar á una puerta con golpes violentos y repetidos.

aporrecearse recp. Magullarse la fruta al cogerla con palos ó al caer al suelo. armador m. Jubon de trage mugeril./[f. 3] 
aro m. Equivale a "boca" en la frase familiar echar por el aro, manducar, comer.

arranarse recp. (Familiar) Caer al suelo con las piernas y brazos estendidos como una rana.

arrear v. n. Caminar de prisa. La voz arrea que el Diccionario califica de interjección para "meter prisa", es el imperativo de este verbo, segun aquí se usa familiarmente.

arreboleras f. Arreboles en el cielo.

arrichante adj. (Familiar) Ufano, hinchado, valenton.

arrufaldarse $r$. (Familiar) Airarse, encolerizarse; usase mas bien en sentido de burla y menosprecio.

artes $\mathrm{m}$. Eslabon, pedernal y yesca para encender fuego. Utensilios ó herramientas de cualquier oficio.

artos m. Planta silvestre espinosa, distinta de la cambronera que seca se usa para reforzar bardas ó setos muertos. Científicamente Paliurus australis.

artillejos m. La constelación de Orión. Salir el sol por los Artillejos. Frase que se aplica a una cosa disparatada, imposible de suceder.

asignado $\mathrm{m}$. El acólito ó monacillo adscrito á una parroquia ó iglesia.

aspearse v. r. Estropearse los pies de andar demasiado.

asperillas f. Sitio en un camino cubierto de losas naturales que forman piso áspero y desagradable.

atochada $\mathrm{f}$. Caballon en su $3^{\mathrm{a}}$ acepción ó malecon que se forma con capas alternadas de tierras y matas de atocha.

atragillado $\mathrm{m}$. El bancal o terreno allanado con la trailla.

atragillar.- Traillar.

averio m. Conjunto de animales de tiro ó de labor./[f. 4]

avilanejo $\mathrm{m}$. Gavilan, ave.

azabaron m. (Tambien se dice acibarón). La caña ó tallo elevado que para florecer produce la azabara (que tambien se llama aqui acibara).

\section{B}

bacon m. Cada uno de los dos trozos de tocino en que se divide la canal de un cerdo al descuartizarlo.

baldosa $\mathrm{f}$. Enlosado que se coloca en las aceras de las calles para comodidad de los transeuntes.

balea $\mathrm{f}$. Escobon rústico para limpiar el grano y barrer las eras.

balear ver. a. Limpiar ó barrer con las balea.

baleo $\mathrm{m}$. Ruedo grande de pleita (en la 4⿳a acepción).

barda f. Seto. Barda viva. Seto vivo.

bardiza f. Barda ó seto bajo y poco fuerte.

bartola f. (Familiar) La panza. Llenar la bartola: comer./ [f. 5]

barzoque m. (Familiar) Diantre; demontre. Anda que te lleve Barzoque, es frase muy usada por aquí.

blanco $\mathrm{m}$. Embutido de cerdo, especial, y de agradable sabor.

bodega $\mathrm{f}$. Sótano, cueva; toda habitación subterranea en las casas.

bolas y bolicas f. Guindillas; pimientos redondos menudos.

bollo m. Pan de harina de maiz ó panizo; algunas veces se amasa en forma de torta delgada y se cuece en el hogar sobre losas de pizarra. 
boquera $\mathrm{f}$. Cauce artificial para el aprovechamiento de aguas pluviales en las tierras de secano.

boria $\mathrm{f}$. Niebla, bruma.

borrar ver. $n$. Removerse las plantas para brotar.

borron $\mathrm{m}$. Boton que se forma en las plantas para indicar el brote al comenzar á moverse la savia.

botihinchado, a adj. fam. Hinchado como una bota por enfermedad ó por grosura.

botijon $\mathrm{m}$. Especie de botija comun en el pais, de boca estrecha y pitón para beber.

bozo m. Bozal para los animales.

broceria f. (De broza) Cualquier clase de comida de poca sustancia y alimento.

bronchera $\mathrm{f}$. Rotura ó agugero grande que se hace en ropa, mueble, pared $\&^{\mathrm{a}}$. burrucho $\mathrm{m}$. Pollino, en la $1^{\underline{a}}$ acepción del Diccionario./[f. 6]

\section{C}

cabo padre m. Verraco.

cachulero m. Especie de cesto cerrado formado de esparto para llevar ó encerrar caracoles.

cagarrache m. Cierto pájaro pequeño.

calabazon $\mathrm{m}$. Calabaza seca y variada que sirve para encerrar vino, aceite y otros usos.

calado sust. $m$. La labor agugereada o calada en papel, tela, madera, metal $\&^{\mathrm{a}}$. calvario $\mathrm{m}$. Santuario construido de ordinario en una altura cerca de las poblaciones, donde terminan los pasos ó estaciones del Via crucis.

campero, a adj. fam. Se usa en la frase Estar ó andar campero que se aplica al que anda suelto, poco unido á toda autoridad y sugeción.

campo $\mathrm{m}$. Las tierras de secano en contraposición a huerta que significa las de regadio.

cantarano m. Mueble antiguo que tiene de cómoda y de papelera.

cantimplora f. Frasco de viage ó caza para llevar aguardiente ú otro licor.

cantusear v. (Familiar) Canturrear o canturriar.

cañahez f. Cañaheja.

caño $\mathrm{m}$. Fuente pública, abrevadero.

cañota $\mathrm{f}$. Planta de sitios pantanosos, especie de caña silvestre ó carrizo.

capacear ver. n. Conducir tierra ú otros materiales en capazos ó espuertas. capaza $f$. Esportilla ó capacha.

capuzar ver. n. Meter la cabeza en el agua. Usa-/[f. 7]se también como reciproco. (Mas conforme con su raiz etimológica caput).

capuzon m. Acción y efecto de capuzar.

caracola $\mathrm{f}$. Toda concha marina univalba.

caracoles! Interjección familiar.

caracha $\mathrm{f}$. Careta y también mascaron.

carachera adj. (Familiar) Se aplica á la muger coqueta que hace cara á muchos. 
caravaqueño, a Natural de Caravaca. U.t.c.s. Perteneciente á esta ciudad (¿Por que no he de poner el gentilicio de esta ciudad ya que no el de otras villas antiguas, populares é importantes de este reino de Murcia omitidas en el Diccionario?).

carral f. Carraco. Estar hecho un carral, se dice familiarmente de la persona muy vieja y achacosa.

carrasca f. La encina comun. (Así se llama generalmente en este pais).

carreton m. Carretilla.

carrizo $m$. La caña comun cuando es delgada y fina.

cascarrar ver. a. Cascar, $1^{\underline{a}}$ acepción. U.t.c.r.

cascaruja f. Cascajo, 2 $2^{\underline{a}}$ acepción.

cavernera $\mathrm{f}$. Colorin ó jilguero.

cejo m. Tajo en un monte ó quebrada de terreno. Refran: Si tu muger se empeña en que te tires de un cejo abajo, ruegale á Dios que estébajo. Fig: Todo lo que forma un corte ó tajo. Así se dice un cejo de agua.

cepo $\mathrm{m}$. Un pie ó planta de vid.

cercha $\mathrm{f}$. La corvadura que forma la madera cerchada.

cerchar ver. recp. Encorvarse las maderas por efecto/[f. 8] del peso, humedad ú otras causas.

cernederas f. Especie de marco de madera en el que se coloca el cedazo para cerner la harina dentro de la artesa.

cetra f. Acetre (mas conforme con su etimologia sistula).

cimbrar ver. a. Cubrir con bóveda.

cimbre $\mathrm{m}$. Boveda de ladrillo y tambien la habitación cubierta por dicha boveda.

cocio m. Vasija grande de barro ancha de boca y estrecha por su base para colar la ropa.

cocon m. Hoyo ó cavidad que forma el agua en un cauce, donde queda depositada despues de seco este.

colador $\mathrm{m}$. Especie de zaranda para cribar los granos.

colaña $\mathrm{f}$. Madero poco grueso y labrado en escuadra de longitud indeterminada.

colar ver. a. Crivar los granos con el colador.

comilona f. (Familiar) Comida muy abundante y tambien francachela.

condolerse ver. rp. Sufrir en cualquier sitio del cuerpo una sensación desagradable que no llega á dolor formal.

condolimiento m. Redolor; la sensación de condolerse.

conduerma f. (Vulgar) Reconcomio.

conrear ver. a. Manejar ó gobernar la casa, hacienda, aperos $\&$ a . Usase tambien como recíproco.

conreo m. Manejo ó gobierno de la casa, hacienda, aperos $\&{ }^{\mathrm{a}}$.

copero. Copete ( $8^{\underline{a}}$ acepción). Así se dice persona de alto copero. Y tomar copero por adquirir proporciones, tomar incremento y elevarse una co-/ $[\mathrm{f}$. 9] sa o persona.

corona de rey f. Girasol ( $1^{\mathrm{a}}$ acepción).

correntilla f. Correndilla. Frase: Andar á correntillas: "ir de prisa en un asunto".

correr burro Frase familiar. Perderse un obgeto, desaparecer por haber sido sustraido. 
corvilla $\mathrm{f}$. Especie de hoz construida a propósito para segar la yerba á flor de tierra.

corvillon m. Instrumento que sirve para cortar o rajar madera ú otros obgetos análogos.

coscoletas (Ir ó llevara) A cuestas ó sobre los hombros de otra persona (por que solo á personas se aplica). Lo mismo da á cuestas que á coscoletas: Refran equivalente al de lo mismo da á cuestas que al hombro.

covadura f. Coyuntura del cuerpo humano ó del de los animales. Fig. Covadura de un negocio: "el punto ó medio mas favorable para resolverlo".

criadilla f. Patata; la planta y el bulbo.

cucala $\mathrm{f}$. Ave de la familia de los cuervos, con el pico rojo; habita en las montañas y es comun en las de este reino de Murcia. Su nombre cientifico Coracia vulgar.

cuco $\mathrm{m}$. Ave de la familia de los buhos; habita en los arboles corpulentos en los que al caer las tardes de verano se oye su grito agudo y monótono. Su nombre cientifico Escopo.

curro, a adj. Majo, 2a acepción.

cutimaña Bicho ó insecto asqueroso y repugnante./[f. 10]

\section{Ch}

chamada f. (Familiar) Indisposición, disgusto o pesar, especialmente si no es de grande importancia.

chanchas marranchas.- Chancharra. Mancharra.

chaparra ó chaparro.- Coscoja.

chaparral m. Coscojal.

chapeton m. Chaparron.

chapina $\mathrm{f}$. Toda clase de concha de mar.

chapineta $\mathrm{f}$. Conchita de mar.

charrada f. (Familiar) Conversación larga y amistosa.

charrador m. (Familiar) El que habla mucho é indiscretamente.

charrar v. (Familiar) Charlar, hablar mucho.

cherro m. (Vulgar) Becerro.

chepado, a adj. (Familiar) Corcovado, a. (El Diccionario trae la voz chepa). chino, a m. y f. (Familiar) Cerdo, cerda.

chipilin, na adj. (Familiar) Chiquitin. Principalmente se aplica á los niños. U.t.c.s.

chirle m. (Familiar) Tajo ó cuchillada.

chisclo ó chiscle m. (Familiar) Sonido de voz agudo y desentonado.

chispeo m. Llovizna, lluvia ligera.

chorrada $\mathrm{f}$. Chorro pequeño. Se aplica al exceso de líquido que se da gratuitamente y de botijuela en la venta de vino y otros caldos.

chorreada y chorreon $m$. Chorreadura.

chulla $\mathrm{f}$. Raja ó pequeña lonja que se arranca del bacalao, carne, tocino $\&$ a.$/[f .11]$

chuscarrar ver. a. Chamuscar. Tostar con exceso un asado ó frito. 
demasiarse ver. rec. Excederse, propasarse de palabra ó de obra.

desforrinchar ver. n. (Familiar) Reventar, estallar con ímpetu en sentido material ó figurado. Usase tambien como recíproco.

desmestar ver. a. Entresacar, coordinar y arreglar obgetos ó negocios confundidos y enredados.

desmesto m. Acción y efecto de desmestar.

desparejo, a, adj. Desigual; lo que no está parejo.

despatarragarse ver. rec. (Familiar) Colocarse estando de pié con las piernas muy abiertas. Fig. Ponerse en lo firme. Salir por lo alto en un trato á ajuste.

desperfollar ver. a. Quitar ó arrancar la perfolla del maiz ú otros frutos.

desperfollo m. La operación de arrancar la perfolla á las panochas del maiz. despicazar v. a. Despizcar.

destilador $\mathrm{m}$. Especie de vasija ó recipiente para dar asiento á las jarras ó alcarrazas, y en el que á la vez se recoje el agua que aquellas destilan.

doblero, a adj. Recio, fuerte ó resistente. Se/[f. 12] aplica á obgetos de suyo delgados como el hilo, hojas de cuchillo, telas $\&^{a}$.

\section{$\mathbf{E}$}

echado á perder Frase familiar que se aplica á la persona que padece algun malestar ó indisposición ligera de salud.

empentar ver. a. (Familiar) Arremeter con ímpetu.

emperador $m$. Pez espada.

emperchar ver. a. Atacar ó acometer á una persona, obgeto ó negocio con intención de rematarlos.

encanarse ver. recip. En los trompos ó peonzas dar vueltas con tal rapidez que no se nota el movimiento y parece se quedan parados. En sentido figurado se aplica familiarmente á la risa ó llanto excesivos que dejan como paralizada la persona que rie ó llora, ó á una locuocidad extraordinaria y continuada.

encobanar ver. a. Colocar y arreglar en el cocio ó cuevano la ropa que se va á colar.

endañarse ver. rec. Enconarse las heridas pequeñas, ó los granos, pústulas \& ${ }^{\underline{a}}$. enfollinarse v. r. (Familiar) Amoscarse, enfadarse.

engato m. (Familiar) Engaño ó trampa en el juego. (De aquí engatar, engatado y engatusado que tiene el Diccionario).

enrobinado, a (Familiar) Figurado: Debil, en-/[f. 13]fermizo, raquítico.

enrobinarse ver. rec. Criar robin los obgetos de hierro ó metal.

enronar y enrunar ver. a. Cubrir las avenidas las tierras de arenas y guijarros. U.t.c.r.

ensabanado $\mathrm{m}$. Persona que sale de noche cubierta de sábanas ó capuces para asustar haciendo la fantasma.

ensobinarse ver. rec. Asobinarse (Familiar) (Parece preferible la $1^{\underline{a}}$ construcción á la $\left.2^{\underline{a}}\right)$.

entrada f. Portal ó zaguan de una casa. 
entrapizarse rec. Entraparse.

enviscarse rec. Ensuciarse con alguna cosa. Usase tambien en sentido figurado.

escabillar v. act. Escardar con el escabillo.

escabillo $m$. Especie de escardillo (1aa acepción).

escandalina y escandalizo (Familiar) Escandalo ó alboroto, principalmente si es de mucho ruido y poca importancia.

esclafar v. a. Escalfar.

escupinajo m. Escupitajo.

escurridor $\mathrm{m}$. Boquete formado a propósito en los cauces ó en las tierras de regadio para que escurran por él las aguas sobrantes.

espulsador $\mathrm{m}$. Zorro en la $6^{\mathrm{a}}$ acepción.

espuma f. Azucarillo./[f. 14]

falsa f. Cámara, desvan, granero.

fandango m. (Figurado y familiar) Alegria, bulla. Lio, confusión, pendencia. Asunto embrollado y dificil.

fileta $\mathrm{f}$. Viga pequeña ó de menores dimensiones que las ordinarias.

filete $\mathrm{m}$. Cuerda delgada de esparto retorcido.

flor f. Grano de panizo que se abre al tostarlo al fuego y se come con un poco de aceite y sal. Panizo de flores: el que sirve para este efecto.

fogarata $f$. Fogata.

fulero, a adj. Chapucero, falso, de mal gusto.

fullir ver. n. Hacer fullerias en el juego.

\section{G}

gachapazo m. Costalazo, zarpazo, zaparrazo.

gachasmigas $\mathrm{f}$. Especie de migas ( $6^{\underline{a}}$ acepción $)$ hechas con harina en vez de pan desmenuzado.

gafarron m. Chamaris.

gallegas f. Zarcillos. (Rustico).

ganchos $\mathrm{m}$. Especie de rastrillo pequeño de hierro con tres ó cuatro puas que usan/[f. 15] los labradores.

gañan $\mathrm{m}$. En este pais solo se aplica esta palabra al que conduce ó gobierna un par de vacuno. Si es de mulas se llama mulero.

garba f. Manojo.

garigola $\mathrm{f}$. Especie de cesto donde llevan los cazadores los hurones amaestrados para cazar los conejos dentro de sus madrigueras.

garranchazo $\mathrm{m}$. Herida hecha con un garrancho.

garrancho m. Espina gruesa ó punta leñosa en las ramas de un arbol ó en maderas.

garranchoso, a adj. Lo que tiene garranchos.

garulla $\mathrm{f}$. Barullo. 
gazpachon, na adj. (Familiar) Se aplica á los muchachos fuertes, sanos y rollizos. U.t.c.s.

glorieta f. Plaza ó sitio en el interior de una población adornado con arboles y jardinillos.

golfos m. Goznes de un sistema especial que permiten quitar y poner las puertas ó ventanas á donde se aplican.

graja $f$. Urraca.

grandaria $\mathrm{f}$. Magnitud, tamaño.

guaraño $m$. Guaran ó garañón.

guarda rural $\mathrm{m}$. El encargado de la custodia de un campo ó partido rural.

guardiania $\mathrm{f}$. El cargo de guarda ó guardian y su ejercicio.

gurguruja m. (Familiar) Susurro ó reunión de muchas personas que hablan á la vez.

gurufalla $\mathrm{f}$. (Familiar) Manjar de poca sustancia y alimento. Usase tambien en plural./[f. 16]

gurullos $\mathrm{m}$. Pedacitos cilindricos que se forman de masa para guisarlos. El guiso que se hace con ellos.

\section{H}

haldeta $\mathrm{f}$. Faldeta ó halda corta en las prendas de vestir.

harpil y jarpil $\mathrm{m}$. Cesto grande y de mallas anchas, fabricado de esparto que se hace para conducir la paja.

hampar y yampar (Familiar) ver. que se usa en la frase estar yampando de hambre, para espresar una extrema miseria ó un hambre vehemente.

heredamiento $\mathrm{m}$. El conjunto de las aguas que riegan un pago ó demarcación; el de las tierras regables y el de los dueños ó usuarios de tales aguas.

hierros $\mathrm{m}$. Trébedes.

horno $\mathrm{m}$. Casa ó establecimiento público donde se cuece el pan que amasan los particulares.

hormiguilla $\mathrm{f}$. La sensación que produce el hormiguear ( $1^{\mathrm{a}}$ acepción) en el cuerpo humano. Aquí se dice siento hormiguilla en esta mano./[f. 17]

hosguear el dia frase. Romper el alba, despuntar el dia.

hurgareño $\mathrm{m}$. Hurgon, ó vara larga para remover y avivar la calda de los hornos.

husaño $\mathrm{m}$. Especie de huso grande sin muescas que sirve para retorcer el hilo.

infantillo $\mathrm{m}$. Infante de coro, en las Iglesias mayores.

jabato, a m. y f. (Familiar) Se dice mal jabato ó mala jabata a la persona de mala indole é inclinaciones. 
jalar v. a. (Familiar) Comer.

jaluza $f$. Hambre viva.

janglon m. Cencerrón./ [f. 18]

jarrero $\mathrm{m}$. Especie de anaquel con aberturas circulares, construido especialmente para colocar las jarras en dichas aberturas.

jetazo m. (Familiar) Bofetón, guantada.

juguesca $\mathrm{f}$. (Familiar) Bronca, juego, alboroto, retozo.

juma $\mathrm{f}$. La hoja del pino.

\section{$\mathbf{L}$}

labor $\mathrm{f}$. Hacienda de campo ó secano.

labraduria f. Labranza.

lapo m. (Familiar) Bofeton ó golpe. (Conforme con su etimol[og]ia alapa).

lastar ver. Padecer, sufir molestias, gastos ó vejaciones ordinariamente como consecuencia de faltas cometidas.

laston $\mathrm{m}$. Yerba campestre, especie de vallico.

lecha $\mathrm{f}$. Pez marino grueso y de buena carne.

leñazo m. (Vulgar) Garrotazo.

losar m. Sitio abundante en losas naturales./[f. 19].

\section{Ll}

llamadera f. Aguijada ( $1^{\underline{a}}$ acepción).

llampear ver. (Vulgar) Relampaguear.

llampo m. (Vulgar) Relámpago.

llandas f. Cajas de lata ó hierro para cocer al horno viandas ú obgetos de reposteria.

llatido $\mathrm{m}$. Voz del perro entre ladrido y ahullido que la usa comunmente cuando levanta y persigue caza.

llatir v. n. Ladrar los perros de este modo.

llovido $\mathrm{m}$. La cantidad de lluvia que cae seguidamente. Así se dice: llovido largo ó corto; Este mes van ya tres llovidos; Este año á los sementeros les ha hecho falta un llovido.

\section{M}

ma (Comun de dos) Voz que la gente del campo, en algunos distritos de este reino, antepone al nombre de las personas ancianas: el ma Anton, la ma Josefa. Equivale á tio en la 3aㅡ acepción.

macoca $f$. Breva seca al sol para comerla.

maderacion $\mathrm{f}$. El maderamen de un edificio./[f. 20]

magenca $\mathrm{f}$. Cava somera á poca profundidad.

magencar ver. a. Cavar la tierra someramente sin profundizar mucho.

majo, a adj. sust. (Vulgar) Querido, da. 
malear (ver. n. familiar) Andar delicado de salud. Se usa en la frase Viene maleando, está male $[a]$ ndo, \&.

manezuela f. Badila del brasero.

manilla f. Manija ( $3^{\text {a }}$ acepción).

manto m (Figurado) Equivale á capa; así se dice manto de agua, de nieve, de flores \& ${ }^{\mathrm{a}}$. Plural- Capas de albardin ó atocha en la[s] cubiertas de las barracas.

mantorna $\mathrm{f}$. La segunda reja ( $3^{\mathrm{a}}$ acepción) que se da en una barbechera.

mantornar ver. a. Labrar las tierras por segunda vez, cruzando la labor primera (para lo cual se torna la mano y de aquí la voz).

margual m. (Se dice tambien marguan y maural). Ruedo en la $4^{\mathrm{a}}$ acepción y tambien aventada en su $4^{\mathrm{a}}$ acepción.

maula $f$. Maza en la $7^{\mathrm{a}}$ acepción.

mayoral $\mathrm{m}$. Persona encargada del cuidado de la hacienda en una casa particular á las órdenes del dueño.

mazacote adj. Equivale á pesado y se aplica lo mismo á una persona, un discurso, á un edificio, $\& c^{\mathrm{a}}$.

medias $\mathrm{f}$. Trato de cultivo en que el dueño pone la finca y alguno de los gastos/[f. 21] de explotación y el colono los restantes, partiendo entre ambos los productos por igual. La parte de frutos correspondiente á cada uno de los contratantes.

merced $\mathrm{f}$. Terreno realengo ó comunal que ha pasado al dominio privado mediante un canon ó graciosamente.

minchirones $\mathrm{m}$. Habas cocidas que se comen en seco.

molla $\mathrm{f}$. La parte suave y blanda de cualquier cosa. Tierra molla: la que es blanda, suave y sin piedras.

mojar ver. Sopar.

mona f. Cierto juego de naipes, en el que hay una carta non, que es la mona, y el que se queda con ella pierde.

monda $\mathrm{f}$. La acción y efecto de mondar. (Aquí se dice, por ejemplo, monda costosa, tiempo de la monda, ya se hizo la monda).

monicaco m. (Familiar) Hominicaco.

moragas $\mathrm{f}$. Granos de trigo asados cuando tierno.

morgon m. Mugron.

morra f. y morron m. Peñasco saliente en la cima de una montaña.

mortaja $\mathrm{f}$. La cantidad de especias de toda clase que para el aderezo de un cerdo se necesita en las matanzas./[f. 22]

\section{$\mathbf{N}$}

naya $f$. Meseta ó rellano de escalera.

nispolero $f$. Nispero.

novatada $\mathrm{f}$. Acción propia del novato en un colegio ú otra corporación, ó que se egerce sobre él abusando de su inesperiencia.

nube f. Nubada, tempestad, nublado. Nube de piedra: Tempestad de granizo y piedra.

nublo m. Nube pequeña y suelta. 
$\tilde{\mathbf{N}}$

ñora f. (Rustico) Noria. (Id.) Pimientos pequeños redondos ó guindillas.

\section{$\mathbf{O}$}

ogañazo adv. (Rustico) Este año presente, en contraposición de antañazo. olleta f. Olla pequeña./[f. 23]

oripié $m$. Base, estribo ó tendido de una sierra ó montaña. (¿Se habrá formado esta palabra del griego oros "monte" y el latino pes? Aquí es de uso comun).

\section{$\mathbf{P}$}

pajar m. Especie de almear para conservar la paja á la intemperie.

pajuza $f$. Pajuz.

pala f. Higuera chumba. Cada una de las hojas de la planta.

palabrotada $\mathrm{f}$. (Familiar) Palabra vana, recia, descompuesta. Usase en sentido despreciativo.

palar m. Sitio plantado de palas ó higueras chumbas.

palera $\mathrm{f}$. Así se llama también la pala ó higuera chumba.

panocho, a m. y f. Persona tosca é inculta.

parada $\mathrm{f}$. Caballon de tierra y broza que al tiempo de regar se forma en las acequias para atajar el agua y dirijirla convenientemente.

pareta $\mathrm{f}$. Pared pequeña.

parranda f. Baile popular de pais. La música y canto con que se baila./[f. 24]

partido $\mathrm{m}$. Trato entre el dueño y el colono de una finca, segun el cual este hace todo $[\mathrm{s}]$ los gastos de cultivo, y el primero se reserva una parte fija de los productos en especie, que es variable. (Así hay partido del sexto, del quinto, del cuarto $\left.\&{ }^{\underline{a}}\right)$. La parte de fruto correspondiente al dueño.

parvada f. Parva, en la $2^{a}$ acepción.

pasos m. Las estaciones del Via-crucis. Andar ó rezar los pasos: Rezar el Viacrucis.

pecho $\mathrm{m}$. Repecho ó pendiente suave en las tierras de labor.

pegote $\mathrm{m}$. Adicción ó intercalación violenta y sin armonia con la obra literaria ó artistica en que se introduce.

pelados m. (Familiar) Los niños ó muchachos de corta edad.

pelanchin $\mathrm{m}$. (Familiar) Pelantrin, hombre de escasos ó ningunos haberes. pelagartar $\mathrm{m}$. Terreno ingrato y dificil para el cultivo que solo cria piedras. pendon $f$. Ramera.

pendonear ver. n. (Familiar) Darse las mugeres á la mala vida.

percanzar ver. anticuado que se usa aun en este pais por la gente rústica con otras muchas palabras de la misma especie, de que esta se pone como ejemplo.

pereta $\mathrm{f}$. Clase de pera pequeñita y temprana.

peretero $\mathrm{m}$. El arbol que produce las peretas. 
perigallo $\mathrm{m}$. Escalera de mano con pie para/ [f. 25] asegurarla, de forma rústica y sirve en los campos para talar los arboles, coger los frutos y otros usos.

pernera f. (Rústica) Piedra de chispa ó pedernal para encender lumbre. perola $\mathrm{f}$. Especie de perol mas pequeño que el ordinario.

picola $\mathrm{f}$. Especie de pico ( $3^{\mathrm{a}}$ acepción) pequeño que tiene un uso especial. pichona $\mathrm{f}$. Un juego de naipes de azar, usado entre la gente vulgar.

pinada $f$. Pinar.

pinatar $m$. Plantio de piños nuevos.

pinato $\mathrm{m}$. Pino joven que no ha llegado á su completo desarrollo.

pinocha $\mathrm{f}$. Ramaje del pino, con su hoja, separado del arbol. (A la hoja del arbol se le llama juma).

piñuelo $\mathrm{m}$. Granillo ó simiente de la uva que se separa al pisarla, y de otros frutos análogos.

piola y piula $\mathrm{f}$. Triquitraque.

piolar v. Pipiar los pollos ó pajaritos. (Gongora dice Pióla cual gorrión/cacareóla cual gallo...).

plantón m. Arbol nuevo, especialmente el olivo.

plantonar $\mathrm{m}$. Plantio de olivos nuevos.

platero, a adj. Que se aplica á los asnos cuyo color es gris plateado. U.t.c.s. pollizo $\mathrm{m}$. Arbol nuevo.

poquitico, a ad. Que se aplica á la persona pusilánime, apocada, que es de poquito. Usase tambien como sustantivo.

portal m. Umbral (1ª acepción) en las puertas de las/[f. 26] casas ó de las habitaciones.

posete m. Destilador ó pié de jarra.

potrear v. (Familiar) Cansar, moler, aburrir con pesadeces.

pozalero $\mathrm{m}$. Tonelero.

primaveral adj. Propio de la primavera o perteneciente á ella.

propio $\mathrm{m}$. Peon que se manda expresamente y ganando horas con alguna carta ó noticia de interes. Ir de propio: Caminar en esta forma. (Figurado) Se dice del que anda muy de prisa. Finca ó propiedad, especialmente si es de importancia.

punchazo m. Punzada.

\section{$\mathbf{Q}$}

quejicon adj. Quejicoso.

quinario $\mathrm{m}$. Ejercicio religioso que se hace en cinco dias como el quinario de la pasión.

quinción f. (Rustico) Disputa ó pendencia/[f. 27].

\section{$\mathbf{R}$}

rabotero, a adj. De caracter agrio y agresivo; que hace ó dice rabotadas. rafalí adj. Que se aplica á cierta clase de carne en su espendición.

ramalazo m. Ramal, en su cuarta acepción aplicado á las tempestades. (Aquí se dice un ramalazo de agua, un ramalazo de granizo \& $\left.{ }^{\underline{a}}\right)$. 
rambla $\mathrm{f}$. Torrentera ó lecho ancho y profundo, seco de ordinario y cubierto de arena, por donde fluyen las aguas de lluvia.

ramblada $\mathrm{f}$. La avenida ó caudal de agua que corre por una rambla y á veces produce inundaciones de importancia.

ramblizo $\mathrm{m}$. Rambla pequeña, de escasas avenidas.

rasera $\mathrm{f}$. Instrumento de cocina que sirve para revolver los fritos, raer las sartenes y artesas y para otros usos.

recancanilla $\mathrm{f}$. Retaila, estrivillo largo y cansado.

regle $\mathrm{m}$. Reglon de albañiles.

regomello m. (Familiar) Reparo, escrúpulo ó desazón interior en hacer ó decir una cosa.

rejón $m$. Reja pequeña ( $2^{\underline{a}}$ acepción) y embutida en la pared.

remanente ad. (Vulgar) Proveniente ó procedente.

remijón m. Saquilada. Corta porción de molienda en la $2^{a}$ acepción. A remijones fr. fam. En veces, en pequeñas cantidades./[f. 28]

remojon m. Mojada, mojadura; por acción y efecto de mojar y mojarse. Darse un remojón fra. fam. Bañarse. Agua con aceite, sal y vinagre en que se sopa pan, de que hace uso la gente del campo como alimento ligero y refrigerante.

remostron m. (Fam.) Emboltorio ó bulto formado por ropas en desorden. rento En la frase a rento equivale a "en arrendamiento".

repropiarse ver. Contenerse, afirmarse el que tropieza ó resbala y va á caer. Fig. Contenerse en un arrebato de ira ú obcecación.

requejo $\mathrm{m}$. Baile anticuado, que tomó su nombre del célebre bailarin murciano Requejo que reformó el bolero.

rescullar y rescullir ver. Resbalar.

rescullon $m$. Resbalon.

resentirse v. rec. Sentir en cualquier parte del cuerpo dolor ligero ó la desazon que queda cuando este termina. (Aun se resiente de sus heridas; se resiente del golpe $\left.\&^{\underline{a}}\right)$.

resultida f. (De resultaró resaltar) Estremecimiento fuerte del cuerpo ó rebote nervioso ocasionado por un susto ó por otra conmoción cualquiera.

retestin $\mathrm{m}$. Olor particular desagradable que por exceso de fuego adquiere un guisado ó cualquier cosa que se cuece.

retestinar verb. Adquirir ó tomar dicho defecto y mal olor. (U.t.c.r.)./[f. 29] retijar ver. Retesar.

rocador $m$. Caña larga con una especie de rocador en un extremo y sirve para coger fruta y otros usos.

rodaja $\mathrm{f}$. En obgetos comestibles equivale a rueda, $4^{\mathrm{a}}$ acepción. Circulo de cuero, fieltro ú otra materia análoga que se aplica algunas veces entre las ruedas de una máquina para evitar el roce ó ajustar el movimiento.

rollo $\mathrm{m}$. Rosquilla, $2^{\mathrm{a}}$ acepción. A pico de rollo: fr. fm. que se emplea para expresar una alimentación escogida y regalona.

rosco $\mathrm{m}$. Especie de rosquilla, aun que no siempre tienen la forma de estas. (Roscon y rosquete parecen derivados mas bien de rosco que de rosca).

roya adj. Roja. Se aplica especialmente á la tierra de este color.

roza $f$. Labor que se hace en las minas al descubierto en forma de zanja mas ó menos profunda. Trabajar a roza abierta: A cielo descubierto formando zanja. 
ruche $\mathrm{m}$. Asno pequeño. Quedarse a ruche: frase fam. Quedarse pobre, perder su fortuna.

rustidera f. (De rostir, ant. asar) Especie de cacerola ó tartera por lo comun de cobre estañado que se emplea para hacer en ella los asados al horno./[f. 30]

sacar el sain á alguno fr. fam. Chupar, esquilmar, agotar su sustancia, intereses, trabajo.

sal de lobo $f$. Cuarcita.

salsear (fam.) Oliscar (2 a acepción) Entrometerse inoportunamente en cosas ó asuntos.

salsero, a m. y f. El que salsea.

saque m. (Familiar) Salida. Buscar el saque a un negocio; no tiene saque. En agricultura, el sitio de la salida del agua en una acequia ó brazal comun.

señor, a m. y f. (Vulgar) El suegro, la suegra.

sipia $\mathrm{f}$. Herraj, orujo.

sobreacequiero $\mathrm{m}$. El encargado del cuidado ó gobierno de una acequia.

solana $f$. La vertiente que mira al medio dia en una montaña.

sopicaldo $\mathrm{m}$. Caldo con sopas muy claras.

surtidero m. Puertecita de escape ó comunicación./[f. 31]

\section{$\mathbf{T}$}

tabla de pan $\mathrm{f}$. Tablero construido á proposito para llevar á cocer los panes al horno.

tajo $\mathrm{m}$. Cuadrilla de jornaleros ó trabajadores especialmente albañiles.

talabante $\mathrm{m}$. El embozo de una capa. Hacer una cosa tiras y talaba[n]tes. fr. fam. Destrozarla, repartirla en fracciones insignificantes.

tambanillo $\mathrm{m}$. Tinglado que se construye á la ligera para resguardarse del sol en las eras y otros descampados y tambien para guardar los frutos desde lo alto.

tapenera f. Alcaparra, planta.

tardión m. (Familiar) Retardo ó retraso, especialmente en llover.

taquilla $\mathrm{f}$. El sitio donde se expenden los billetes para el teatro ú otras diversiones.

taquillero $\mathrm{m}$. Expendedor de dichos billetes.

telo $\mathrm{m}$. Tela, $7^{\mathrm{a}}$ acepción. Coagulo tenue que se forma en la superficie de algun liquido.

tendida $\mathrm{f}$. Mantel de lana de colores que usa para comer la gente ordinaria. tendido $\mathrm{m}$. Tela de lana fabricada expresamente para abrigar los panes en masa.

tenor m. Guitarra mediana de son de tenor.

testarozo m. (faml?) Testarada.

tierra en las frases siguientes: tierra blanca, la que no tiene arbolado; tierra de boquera, la de secano/ [f. 32] que disfruta del beneficio de avenidas; tierra de gotera, la que no goza de otra agua que la del cielo. 
timple m. (Vulgar) Tiple, guitarra pequeña de voces agudas.

tinglado $\mathrm{m}$. Tablado ó cobertizo que se improvisa á la ligera y de consiguiente de poca resistencia. Descomponer el tinglado: fr. fam. por descomponer ó desbaratar un negocio.

tormo $\mathrm{m}$. Terron de tierra, especialmente los que se forman al labrar o cavar.

torradas f. Parrandas; música y baile popular.

torreta $\mathrm{f}$. Torre o mirador en las casas particulares.

tragilla $\mathrm{f}$. Trabilla.

traspol $\mathrm{m}$. Piso de una habitación formado unicamente con yeso enlucido. trenque $\mathrm{m}$. Portillo que abre el agua en una acequia ó bancal.

trigarral m. (Familiar) Sementero de trigo que esta espeso y lozano.

$\mathbf{U}$

umbria $f$. La vertiente que mira al norte en una montaña./[f. 33]

V

vergas f. (Rústico) Zarcillos.

$\mathbf{Z}$

zagal, a m. y f. (Rústico) Niño ó muchacho antes de la adolescencia.

zafero $m$. Palanganero.

zafran m. Azafran.

zamarrazo $m$. (Familiar) Trastazo.

zaranda $\mathrm{f}$. Pequeña criba de hoja de lata que se usa en las cocinas para limpiar el arroz y otras semillas.

zarangollo $\mathrm{m}$. Fritada de calabaza, cebolla y tomate a los que suelen añadirse otros adherentes.

zargallote, a m. y f. Tagarote. Hombre ó muger fornidos y corpulentos.

zimboba f. (Vulgar) Zamboa.

zofra $\mathrm{f}$. Correa ancha que sostiene las varas de un carro sobre el sillin de la caballeria.

zonga f. (Familiar) Hacer zonga. Hacer novillos.

zorollo, a adj. Que se aplica á los frutos que no han llegado á su sazón completa. Así se/[f. 34] dice trigo zorollo, cebada zorolla, fruta zorolla.

zunzun m. (Familiar) Runrun, rumor.

zunzunearse ver. Susurrarse, $2^{2}$ acepción.

[f. 35] Voces usadas en el lenguage comun de este reino de Murcia, que se encuentran en el Diccionario con este caracter y se ha creido necesario corregir ó enmendar 
alporchon Es voz que unicamente se usa en Lorca y se aplica no solo al edificio donde se subasta el agua para regar las tierras, sino tambien al acto de dicha subasta.

bardomera Generalmente se dice baldomera, aunque algunos rústicos pronuncia bardomera, por corrupción de la $l$ en $r$, comun en España en esta clase de gente.

barraca $\mathrm{f}$. Vivienda rústica usada en varios pueblos de la provincia de Murcia, especialmente en la huerta de la capital, de planta cuadrilonga, armazon de madera y cañizos, las paredes de adobes o cañas rebozadas con barro ó yeso y la cubierta de atocha ó albardin elevada en el centro en forma de tejado á dos aguas.

barracon $m$. Barraca construida mas á la ligera y ordinariamente mas pequeña que las comunes y destinada generalmente á vivienda de los animales.

a bonico adv. Quedo (2 $2^{-}, 3^{-a}$ y $4^{\text {a }}$ acepción).

cachulera $\mathrm{f}$. Habitación mezquina, sucia y retirada.

caracol chupalandero ó chupadero m. El de tamaño/[f. 36] menor que el ordinario que se come chupandolo.

enrastrar v. a. Colocar en rastras o sartas los capullos de seda, ajos, cebollas, pimientos $\& \underline{a}$.

escaldufar v. a. Escaldar ligeramente. Chamuscar.

fosca $f$. Bosque ó malezas enmarañadas.

mampirlan $\mathrm{m}$. Liston de madera que en las escaleras de yeso y loseta ordinaria se coloca en la arista que forman los escalones.

perfolla $\mathrm{f}$. La hoja que cubre en varias capas o folículos el fruto del maiz, cebolla, ajo y otras plantas, este seca o verde. (Esta voz de uso general aquí ajusta exactamente á su raiz etimológica Perifolia). Paja de maiz.

quijero m. Cada uno de los dos malecones ó caballones de tierra que forman la caja de una acequia ó brazal.

tapana f. (Tápena es como generalmente se dice) y su aplicación mas comun es al alcaparron.

[f. 37] Voces usadas en el lenguage comun de este reino de Murcia que el Diccionario califica de provinciales de otros reinos, y que lo son tambien de este

Arag. Brazal.

Arag. Caracola (El caracol terrestre de concha prolongada, bulimus)

Andal. Coco (percal)

Andal. Cuartero.

Andal. Curdo.

Arag. Mediero.

Andal. Raspinegro.

Andal. Regelear.

Andal. Regeleo.

Andal. Sesada.

Arag. Silleta (por jamuga)

Arag. y Nav. Uva (por racimo de uvas)

Arag. Canalera (por canalón) 
[f. 38] Voces que suenan en el Diccionario como provinciales de Murcia y no se usan en este reino; al menos en el dia

\section{Algevena \\ Brote \\ Burengue \\ Capolar \\ Carricoche (Por carro de la basura)}

Cisca Por carrizo (Hay una planta que llaman sisca, distinta del carrizo).

Mantillón

Mojada (Como se usa mojar por sopar, una mojada equivale á un pedazo de pan sopado en caldo).

\section{Vargano}

Matacandil (Langosta de mar) 